\title{
ANALISIS PEMBOBOTAN T2 TURBO SPIN ECHO (TSE) BRAIN MRI POTONGAN AXIAL DENGAN PENGGUNAAN SENSITIVITY ENCODING (SENSE) DAN TANPA PENGGUNAAN SENSE : EVALUASI PADA SIGNAL TO NOISE RATIO (SNR) DAN SCAN TIME
}

\section{ANALYSIS OF TURBO SPIN ECHO (TSE) T2 WEIGHTING BRAIN MRI AXIAL SLICES WITH SENSITIVITY ENCODING (SENSE) AND WITHOUT SENSE USAGE: EVALUATION ON SIGNAL TO NOISE RATIO (SNR) AND SCAN TIME}

\author{
Fani Susanto ${ }^{1)}$, A. Gunawan Santoso ${ }^{2)}$, Bagus Abimanyu ${ }^{3)}$ \\ ${ }^{1,3)}$ Health Polytechnics of Semarang-Indonesia \\ ${ }^{2)}$ Radiologi Installation Dr Kariadi Semarang Hospital \\ e-mail: fanisusanto28@gmail.com
}

\begin{abstract}
Background: On examination brain MRI often finds non-cooperative patients, requiring rapid acquisition techniques. The parallel imaging sensitivity encoding (SENSE) technique utilizes spatial RF coated phased array information to reduce acquisition time by reducing the K space sampling line to produce good quality and spatial resolution, but has a limitation of signal-to-noise ratio (SNR) reduction. SENSE is used with MRI sequence pulses one of them turbo spin echo (TSE). The purpose of this study was to determine the difference of SNR and scan time on TSE T2 weighting brain MRI axial slices between use SENSE and without SENSE.

Methods: This research is quantitative study with experimental approach. The data were collected from May to June 2016 at the Radiology Installation of Premier Bintaro Hospital by calculating the SNR through the software for the region of interest (ROI) and calculating the scan time through the scan timer on the workstation monitor. Data analysis was done by statistical test with SPPS 16 application using paired T-test and descriptive

Results: From the result of statistical test, it is known that SNR at TSE T2 weighting between with and without SENSE is obtained p-value $0,000(\mathrm{p}<0,05)$. This is because the encoding of the both image are different, On TSE T2 weighting image without SENSE there is the use $180^{\circ}$ pulses approaching the effective TE so the shallow gradient produces maximum echo, while on TSE T2 weighting with SENSE there is a reduction of phase encoding row in $\mathrm{K}$ space and the presence of g-factor causes the SNR to decrease. From descriptive analysis result, is known that scan time on TSE T2 weighting between with and without SENSE usage is obtained by reduction of scan time for 1 minute 24 seconds $(49,01 \%)$. This is because the acquisition technique between the both image are different, on the TSE T2 weighting without SENSE there is ETL in charging K space, whereas on the TSE T2 Weighting with SENSE there is R-factor causing the sampling not to fill all K space so that scanning time is reduced.

Conclusion: There are SNR and scan time differences on TSE T2 weighting brain MRI of the axial slices with SENSE and without SENSE usage.
\end{abstract}

Keywords : SENSE, SNR, Scan Time, T2 TSE, Brain MRI

\section{PENDAHULUAN}

Saat ini pemeriksaan magnetic resonance imaging (MRI) merupakan pemeriksaan rutin di rumah sakit besar. Pada prinsipnya hampir seluruh organ tubuh dapat diperiksa dengan MRI. Pemeriksaan MRI 90\% dilakukan pada organ kepala dan vertebra sedangkan sisanya $10 \%$ untuk pemeriksaan organ yang lain (Rasad, 2011). Pada pemerikaan MRI kepala, pulsa sekuens yang digunakan salah satunya adalah turbo spin echo (TSE) dengan pembobotan T2 (Westbrook, 2014).

Pulsa Sekuens adalah serangkaian even yang meliputi pulsa radio frekuensi (RF), pengaktifan gradien dan pengumpulan sinyal yang dilakukan untuk menghasilkan gambaran MRI. Pulsa sekuens yang biasa digunakan adalah sekuens TSE. TSE adalah sekuens spin echo dengan multipel $180^{\circ}$ refokus radio frekuensi (RF) pulsa setelah satu pulsa $90^{\circ}$ untuk menghasilkan deretan echo (Bitar dkk, 2006). Menurut Westbrook (2014), sekuens TSE banyak digunakan untuk citra pembobotan T2 dikarenakan nilai scan time yang digunakan menjadi singkat dan juga penggunaan sekuens TSE akan meningkatkan nilai signal to noise ratio (SNR).

Signal to noise ratio (SNR) dan scan time merupakan dua faktor yang menentukan kualitas citra. SNR adalah perbandingan antara besarnya amplitudo sinyal dengan amplitudo noise. Sedangkan scan time adalah waktu dalam melengkapi data akuisisi. Nilai SNR dan scan time sangat berpengaruh terhadap kualitas citra yang dihasilkan. Nilai SNR sangat tergantung dari sinyal yang didapatkan dari organ, semakin tinggi nilai sinyal yang ada pada organ maka nilai SNR juga akan semakin tinggi. Sedangkan nilai scan time sangat penting untuk diperhatikan karena waktu scanning yang lama menyebabkan kemungkinan adanya pergerakan pasien selama akuisisi yang tentunya mempengaruhi kualitas citra yang akan dihasilkan (Westbrook dkk, 2011).

Pemeriksaan MRI kepala khususnya brain, potongan axial merupakan "gold standard" untuk pemeriksaan MRI 
brain dikarenakan dapat memperlihatkan organ lebih jelas dibandingkan dengan potongan yang lainnya (Liney, 2006). Pada pemeriksaan MRI brain, seringkali menjumpai pasien yang merasa kurang nyaman dikarenakan lamanya pemeriksaan, sehingga menyebabkan citra yang dihasilkan menjadi kurang optimal dan mengurangi informasi diagnostik. Salah satu cara yang dapat mengurangi scan time adalah dengan menggunakan teknik akuisisi paralel atau teknik paralel imaging. Teknik paralel imaging yang biasa digunakan salah satunya adalah sensitivity encoding atau SENSE.

SENSE adalah salah satu teknik paralel imaging yang menggunakan citra yang dibentuk oleh koil phased array. Rekonstruksi SENSE dapat mempercepat pengisian $K$ space sehingga menyebabkan pengurangan scan time (Dale dkk, 2015).

Rekonstruksi citra SENSE menghasilkan kualitas citra dari segi kontras dan spasial resolusi yang sama dengan rekonstruksi citra standar dan memakan waktu yang dibutuhkan hanya setengahnya, akan tetapi dapat mengurangi nilai sinyal pada citra anatomi. Pengurangan SNR pada rekonstruksi SENSE dipengaruhi oleh penggunaan reduction factor $(\mathrm{R})$ atau jumlah elemen pada koil phased array yang digunakan (Glockner dkk, 2005). Teknik paralel imaging memanfaatkan elemen pada multipel koil penerima phased array dengan mengurangi baris phase encoding pada $K$-space sesuai faktor $1 / \mathrm{R}$ sehingga sampling tidak mengisi semua $K$ space. SENSE menyebabkan waktu akuisisi data menjadi berkurang dan menjadi lebih cepat sesuai $\mathrm{R}$ yang digunakan (Morelli dkk, 2011).

Di Unit Radiologi Rumah Sakit Premier Bintaro, pesawat MRI yang digunakan adalah Philips Achieva 1,5 Tesla. Pada pesawat tersebut terdapat pilihan teknik paralel imaging yaitu dengan menggunakan SENSE dan tanpa menggunakan SENSE. Protokol pemeriksaan MRI brain rutin di Unit Radiologi Rumah Sakit Premier Bintaro, teknik paralel imaging SENSE hanya digunakan pada sekuens diffusion weighted imaging (DWI). Sedangkan pada sekuens yang lain khususnya pada pembobotan T2 sekuens TSE, teknik paralel imaging SENSE selalu tidak digunakan. Padahal secara teori penggunaan SENSE memiliki keuntungan dari segi scan time yang menjadi lebih singkat.

\section{METODE}

Jenis penelitian ini adalah penelitian kuantitatif dengan pendekatan eksperimental. Pengambilan data dilakukan pada bulan Mei sampai Juni 2016 di Unit Radiologi Rumah Sakit Premier Bintaro dengan pesawat MRI berkekuatan 1,5 Tesla. Populasi dan sampel penelitian adalah citra MRI brain dari dua kelompok berpasangan citra pembobotan T2 TSE antara penggunaan SENSE dengan tanpa SENSE dari 19 orang pasien, dengan kriteria inklusi pasien MRI brain dengan klinis, pria atau wanita kooperatif dengan usia 20-60 tahun dan bersedia berpartisipasi dalam penelitian, sedangkan untuk kriteria eksklusinya adalah penderita claustrophobia dan diberikan obat anastesi.

Penilaian citra MRI brain untuk penghitungan nilai SNR dilakukan dengan menggunakan software untuk ROI pada citra pembobotan T2 TSE MRI brain potongan axial baik menggunakan SENSE maupun tanpa SENSE setinggi thalamus untuk anatomi cortex cerebri, basal ganglia, thalamus dan setinggi pons untuk anatomi pons dan cerebellum, serta ROI pada noise background. Penghitungan SNR dengan ROI sebesar $0,05 \mathrm{~cm}^{2}$ untuk per kriteria anatomi dan $0,2 \mathrm{~cm}^{2}$ untuk noise background (lihat Gambar 1). Penghitungan SNR citra SENSE yaitu $\mathrm{SNR}_{\mathrm{TPI}}=\frac{\text { 5NRstandar }}{\mathrm{g} \sqrt{\mathrm{R}}}$ dimana TPI : Teknik paralel imaging, g : geometry factor dan $\mathrm{R}$ : reduction factor. Penilaian citra untuk penghitungan nilai scan time dilakukan dengan menggunakan penghitung waktu scanning yang ada di monitor workstation.

Analisis data dilakukan uji statistik dengan software SPSS 16 menggunakan uji normalitas data Kolmogorov Smirnov dikarenakan data banyak (>50) untuk mengetahui data terdistribusi normal atau tidak. Selanjutnya dilakukan uji T-berpasangan dikarenakan data berskala rasio dari dua sampel berpasangan untuk mengetahui tingkat perbedaan SNR pada pembobotan T2 TSE MRI brain axial antara penggunaan SENSE dengan tanpa SENSE dengan nilai $\alpha=0,05(\mathrm{p}<0,05)$.

Analisis secara deskriptif dilakukan, dikarenakan data nilai scan time tidak variatif (konstan) sehingga tidak dapat dilakukan dengan uji SPSS, dilakukan dengan melihat prosentase yang dihasilkan untuk mengetahui perbedaan scan time pada pembobotan T2 TSE MRI brain axial antara penggunaan SENSE dengan tanpa SENSE.

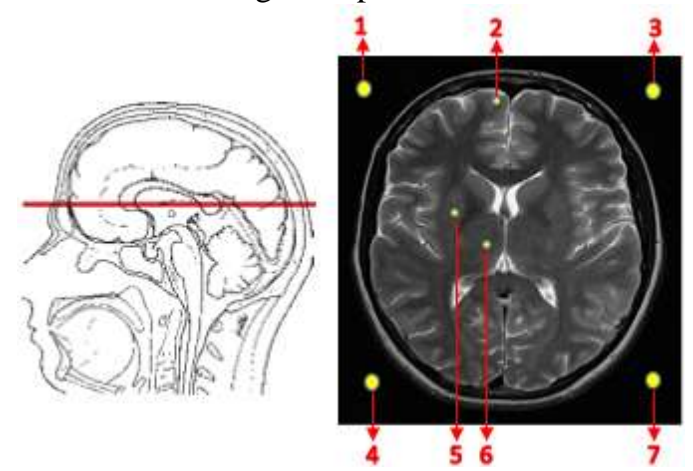

Gambar 1. (A) Penghitungan nilai sinyal citra pembobotan T2 TSE MRI brain potongan axial setinggi thalamus, Noise 1 (1), Cortex cerebri (2), Noise 2 (3), Noise 3 (4), Basal ganglia (5), Thalamus (6), Noise 4 (7).

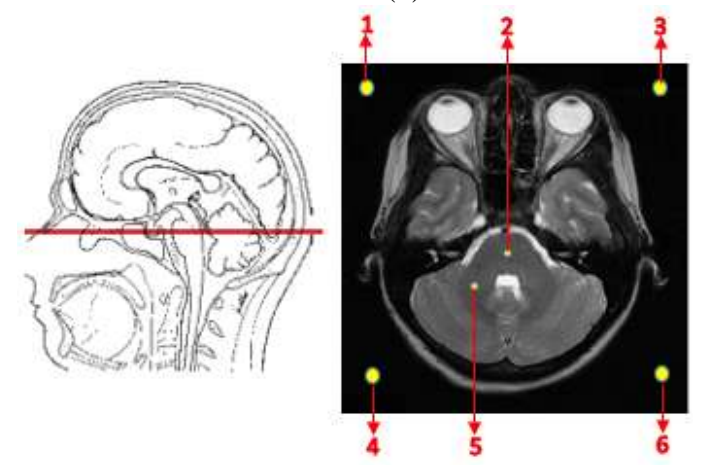

Gambar 2. (B) Penghitungan nilai sinyal citra pembobotan T2 TSE MRI brain potongan axial setinggi pons, Noise 1 (1), Pons (2), Noise 2 (3), Noise 3 (4), Cerebellum (5), Noise 4 (6) 


\section{HASIL}

Penelitian ini dilakukan terhadap 19 orang pasien yang dilakukan pemeriksaan MRI brain potongan axial antara penggunaan SENSE dengan tanpa SENSE dengan total waktu penelitian untuk masing-masing pasien terdapat penambahan sekitar 2-3 menit dari pemeriksaan rutin.

Tabel 1. Deskripsi sampel penelitian

\begin{tabular}{cccc}
\hline \multirow{2}{*}{ Kategori } & Klasifikasi & Jumlah & $\begin{array}{c}\text { Persentase } \\
(\%)\end{array}$ \\
\hline \multirow{2}{*}{ Jenis } & laki-laki & 9 & 47,4 \\
Kelamin & perempuan & 10 & 52,6 \\
\cline { 2 - 4 } & Total & 10 & 100 \\
\hline \multirow{3}{*}{ Umur } & $21-40$ tahun & 9 & 47,4 \\
& $41-60$ tahun & 10 & 52,6 \\
\cline { 2 - 4 } & Total & 10 & 100 \\
\hline \multirow{6}{*}{ Klinis } & Vertigo & 8 & 42,1 \\
& Cephalgia & 8 & 42,1 \\
& Cerebrovascular & 2 & 10,5 \\
& Disease (CVD) & 1 & 5,3 \\
\cline { 2 - 4 } & Abses cerebri & 1 & 100 \\
\cline { 2 - 4 } & Total & 19 & \\
\hline
\end{tabular}

Uji normalitas data dilakukan dengan menggunakan uji Kolmogorv-Smirov dikarenakan data banyak (>50) untuk mengetahui data terdistribusi normal atau tidak.

Tabel 2. Hasil uji normalitas data nilai SNR secara keseluruhan citra pembobotan T2 TSE MRI brain potongan axial antara penggunaan SENSE dengan tanpa SENSE

\begin{tabular}{cc}
\hline $\begin{array}{c}\text { Nilai SNR secara keseluruhan } \\
\text { citra T2 TSE axial }\end{array}$ & $\begin{array}{c}\text { Nilai kemaknaan } \\
(p \text {-value })\end{array}$ \\
\hline Tanpa SENSE & 0,103 \\
Menggunakan SENSE & 0,068 \\
\hline
\end{tabular}

Berdasarkan tabel 2, data dua kelompok citra T2 TSE antara penggunaan SENSE dan tanpa SENSE didapatkan $\mathrm{p}>0,05$ sehingga dapat dikatakan terdistribusi normal, selanjutnya dapat dilakukan uji T-berpasangan.
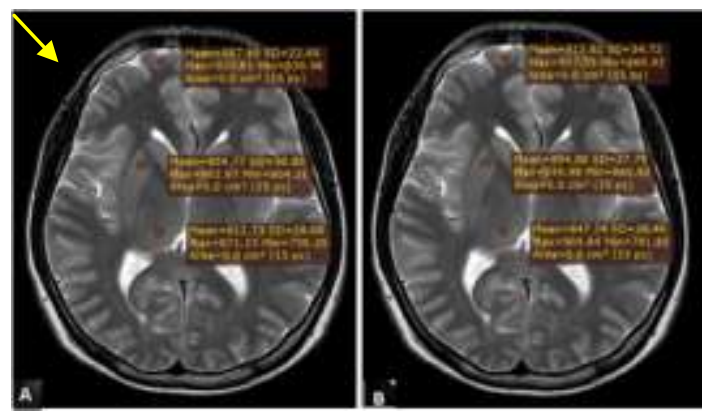
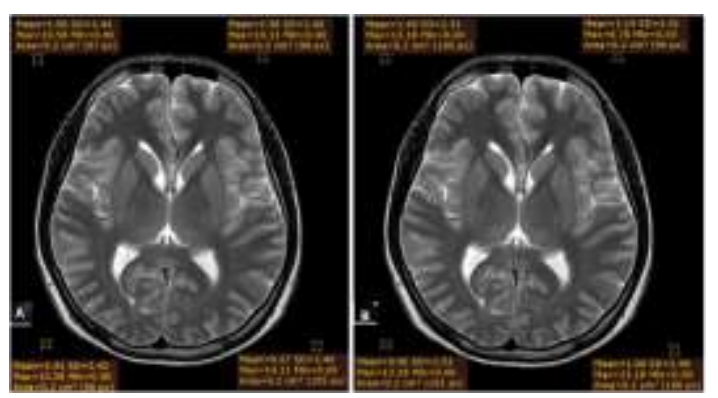

Gambar 3. Tanda panas atas : sinyal rata-rata anatomi pons dan cerebellum pada potongan setinggi thalamus citra pembobotan T2 TSE MRI brain axial tanpa SENSE (A) dan menggunakan SENSE (B). Tanda panah bawah : Standar deviasi noise potongan setinggi thalamus citra pembobotan T2 TSE MRI brain axial tanpa SENSE (A) dan menggunakan SENSE (B)

Tabel 3. Hasil penghitungan nilai rata-rata SNR per kriteria anatomi citra pembobotan T2 TSE MRI brain potongan axial antara penggunaan SENSE dengan tanpa SENSE dari 19 orang pasien

\begin{tabular}{ccc}
\hline \multirow{3}{*}{ Anatomi } & $\begin{array}{c}\text { Nilai rata-rata SNR dan standar deviasi } \\
\text { citra pembobotan T2 TSE } \\
\text { MRI brain potongan axial }\end{array}$ \\
\cline { 2 - 3 } & $\begin{array}{c}\text { Tanpa SENSE } \\
(\text { Mean } \pm \mathrm{SD})\end{array}$ & $\begin{array}{c}\text { Menggunakan SENSE } \\
(\text { Mean } \pm \text { SD })\end{array}$ \\
\hline Cortex cerebri & $375,75 \pm 18,23$ & $263,84 \pm 11,71$ \\
Basal ganglia & $339,98 \pm 10,77$ & $233,94 \pm 11,60$ \\
Thalamus & $315,51 \pm 17,83$ & $216,31 \pm 12,93$ \\
Pons & $316,11 \pm 16,90$ & $219,72 \pm 10,28$ \\
Cerebellum & $337,30 \pm 17,22$ & $231,38 \pm 11,62$ \\
\hline
\end{tabular}
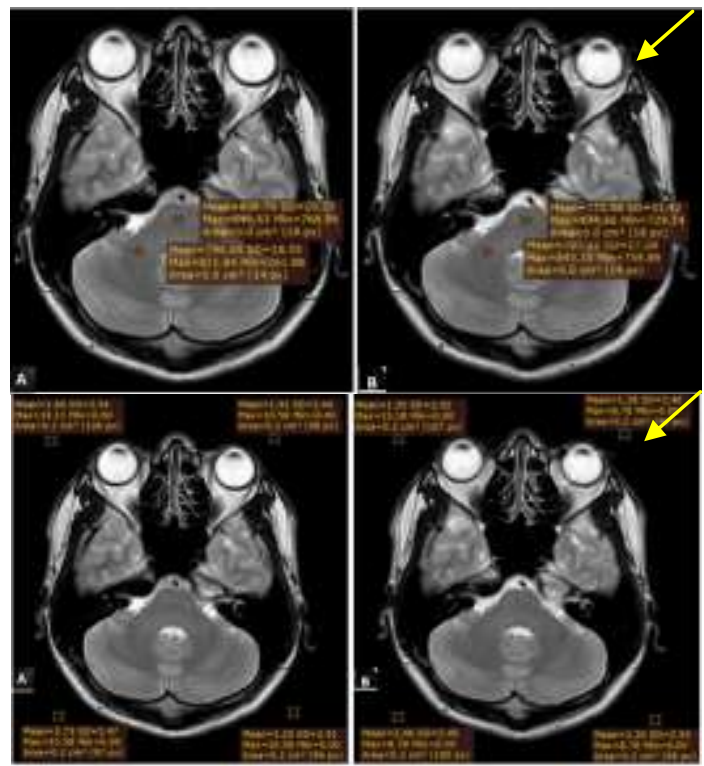

Gambar 4. Tanda panah atas : Sinyal rata-rata anatomi pons dan cerebellum pada potongan setinggi pons citra pembobotan T2 TSE MRI brain axial tanpa SENSE (A) dan menggunakan SENSE (B). Tanda panah bawah : Standar deviasi noise potongan setinggi pons citra pembobotan T2 TSE MRI brain axial tanpa SENSE (A) dan menggunakan SENSE (B)

Hasil penghitungan SNR secara keseluruhan pada citra pembobotan T2 TSE MRI brain potongan axial antara penggunaan SENSE dengan tanpa SENSE dianalisis dengan 
menggunakan uji T-berpasangan untuk mengetahui adanya perbedaan nilai SNR.

\begin{tabular}{cc} 
Tabel 4. Hasil uji T-berpasangan nilai SNR secara keseluruhan \\
\hline $\begin{array}{c}\text { Nilai SNR secara keseluruhan citra } \\
\text { T2 TSE } \text { axial }\end{array}$ & $\begin{array}{c}\text { Nilai kemaknaan } \\
(p \text {-value })\end{array}$ \\
\hline $\begin{array}{c}\text { Tanpa SENSE } \\
\text { Menggunakan SENSE }\end{array}$ & 0,000 \\
\hline
\end{tabular}

Berdasarkan tabel 4, diperoleh nilai kemaknaan ( $p$-value) 0,000 yang berarti terdapat perbedaan SNR yang signifikan citra pembobotan T2 TSE antara penggunaan SENSE dengan tanpa SENSE.

Data tabel 5 merupakan hasil perbedaan scan time pada pembobotan T2 TSE MRI brain potongan axial antara penggunaan SENSE dengan tanpa SENSE.

Tabel 5. Hasil nilai rata-rata scan time pada pembobotan T2 TSE MRI brain axial antara penggunaan SENSE dengan tanpa SENSE dari 19 orang pasien

\begin{tabular}{|c|c|c|c|c|}
\hline \multirow{2}{*}{ Citra } & \multicolumn{2}{|c|}{$\begin{array}{l}\text { Nilai rata-rata scan time } \\
\text { (menit:detik) }\end{array}$} & \multirow{2}{*}{$\begin{array}{c}\text { Reduksi } \\
\text { scan time } \\
\text { (menit:detik) }\end{array}$} & \multirow{2}{*}{$\begin{array}{c}\text { Persentase } \\
(\%)\end{array}$} \\
\hline & $\begin{array}{l}\text { Tanpa } \\
\text { SENSE }\end{array}$ & $\begin{array}{l}\text { Menggunakan } \\
\text { SENSE }\end{array}$ & & \\
\hline Pembobotan & & & & \\
\hline $\begin{array}{l}\text { T2 TSE } \\
\text { MRI brain } \\
\text { axial }\end{array}$ & $2: 53$ & $1: 29$ & $1: 24$ & 49,01 \\
\hline
\end{tabular}

\section{DISKUSI}

Penelitian yang telah dilakukan pada 19 orang pasien MRI brain dengan klinis pada pembobotan T2 TSE MRI brain potongan axial antara penggunaan SENSE dengan tanpa SENSE serta memperoleh hasil penilaian citra dengan menghitung nilai SNR dan scan time. Hasil penilaian citra tersebut sudah diolah secara komputerisasi menggunakan software SPSS 16.

Hasil uji normalitas data nilai SNR secara keseluruhan dengan uji Kolmogorov-Smirnov diperoleh tingkat kepercayaan (confident level) 95\% $(\alpha=5 \%)$, menunjukkan bahwa nilai kemaknaan ( $p$-value) lebih besar dari $\alpha(\mathrm{p}>0,05)$ dari dua kelompok data masing-masing pembobotan T2 TSE menggunakan SENSE sebesar 0,068 dan tanpa SENSE yaitu 0,103. Menurut Dahlan (2013), suatu data dapat dikatakan berdistribusi normal jika memiliki nilai kemaknaan ( $p$-value) lebih dari 0,05. Berdasarkan hasil uji normalitas data nilai SNR secara keseluruhan dengan menggunakan uji Kolmogorov-Smirnov, bahwa data dari masing-masing pembobotan T2 TSE antara penggunaan SENSE dengan tanpa SENSE adalah berdistribusi normal.

Berdasarkan hasil SPSS uji T-berpasangan menyatakan Ho ditolak, yaitu ada perbedaan pada nilai SNR secara keseluruhan dengan nilai kemaknaan 0,000 ( $\mathrm{p}<0,05)$ pada pembobotan T2 TSE MRI brain potongan axial antara penggunaan SENSE dengan tanpa SENSE.

Perbedaan tersebut dikarenakan encoding pada citra pembobotan T2 TSE antara penggunaan SENSE dengan tanpa SENSE yang berbeda. Pada citra pembobotan T2 TSE tanpa SENSE tidak terjadi adanya pengurangan baris phase encoding pada sampling time setiap voxel. Sedangkan pada citra pembobotan T2 sekuens TSE menggunakan SENSE terjadi adanya pengurangan baris phase encoding pada sampling time setiap voxel dari elemen koil phased array, sehingga amplitudo sinyal pada organ anatomi yang dihasilkan menjadi turun. Oleh karena itu pada citra pembobotan T2 TSE menggunakan SENSE memiliki SNR yang lebih rendah dibandingkan dengan citra pembobotan T2 TSE tanpa SENSE

Hal ini sesuai dengan Westbrook dkk (2011), bahwa peningkatan sinyal pada citra pembobotan T2 sekuens TSE standar tanpa SENSE terjadi karena pada gradien phase encoding tanpa adanya pengurangan, melainkan penggunaan pulsa $180^{\circ}$ mendekati TE efektif yang dipilih sehingga pada shallow gradien menghasilkan echo atau sinyal pada level maksimal. Penurunan SNR pada citra pembobotan T2 TSE menggunakan SENSE sesuai dengan Ryan dkk (2005), bahwa konsep teknik paralel imaging menggunakan koil surface phased array dan rekonstruksi algoritma menghilangkan artefak wrapping atau aliasing, sehingga mendapatkan sinyal yang informatif dari koil di luar FOV pada elemen koil individu. Pengurangan baris phase encoding dibutuhkan untuk mengisi $K$ space citra pada setiap elemen koil, defisiensi potensial dipenuhi oleh penghilangan informasi wrapping untuk menghasilkan spasial resolusi citra tinggi. Proses SENSE inilah yang menyebabkan pengurangan sinyal pada citra pembobotan T2 TSE menggunakan SENSE.

Penurunan nilai SNR pembobotan T2 sekuens TSE menggunakan SENSE sebesar 1/1,41 dikarenakan penggunaan reduction factor 2 dan geometry factor 1 . Hal ini sesuai dengan Willineck dkk (2003), bahwa rekonstruksi SENSE mengurangi baris phase encoding menggunakan SENSE reduction factor $(\mathrm{R})$. SNR berkebalikan secara proporsional dari R. Peningkatan noise terjadi ketika hubungan geometry dari sensitivitas koil tidak optimal. Peningkatan noise spesifik pada SENSE ini disebut geometry factor (g) local. Oleh karena itu, nilai SNR pada citra SENSE dibandingkan dengan citra standar tanpa SENSE akan mengikuti rumus yaitu $\mathrm{SNR}_{\mathrm{SENSE}} / \mathrm{SNR}_{\text {standar }}=1 / \mathrm{g} \sqrt{\mathrm{R}}$. Penggunaan reduction factor 2 dan geometry factor 1 menyebabkan penurunan SNR sebesar $1 / 1,41$. Nilai SNR yang lebih rendah pada sekuens dengan menggunakan akuisisi SENSE tidak mengganggu pada interpretasi citra diagnostik dan tidak menghalangi secara pandangan visual pada lesi yang dibutuhkan pada citra SENSE.

Penurunan SNR pada citra pembobotan T2 TSE menggunakan SENSE tidak menyebabkan kualitas citra yang berbeda dibandingkan pada citra pembobotan T2 TSE standar tanpa SENSE. Dikarenakan dengan pengurangan FOV dan adanya sensitivitas spasial dari koil phased array yang digunakan untuk menyediakan informasi spasial pada citra yang akan dibutuhkan dalam transformasi fourier MR imaging. Hal ini sesuai dengan Glockner dkk (2005), bahwa teknik paralel imaging menggunakan gradien yang lebih cepat dan kuat untuk meningkatkan waktu akuisisi, sensitivitas spasial dari koil phased array digunakan untuk menyediakan spasial informasi pada citra yang akan dibutuhkan dalam transformasi 
fourier MR imaging atau dengan kata lain, teknik paralel imaging menyebabkan pengurangan baris phase encoding dengan tetap menghasilkan kualitas dan spasial resolusi yang baik.

Penggunaan teknik SENSE pada pembobotan T2 sekuens TSE pemeriksaan MRI brain potongan axial dapat diterapkan pada pembobotan T2 TSE standar tanpa SENSE yang biasa digunakan, walaupun mengalami penurunan nilai SNR akan tetapi tetap menghasilkan informasi citra yang tidak berbeda.

Berdasarkan hasil uji secara deskriptif menunjukkan bahwa terdapat perbedaan nilai scan time pada pembobotan T2 TSE MRI brain potongan axial antara penggunaan SENSE dengan tanpa SENSE dengan selisih waktu akuisisi sebesar 1 menit 24 detik $(49,01 \%)$.

Perbedaan tersebut dikarenakan teknik akuisisi antara menggunakan SENSE dan tanpa menggunakan SENSE yang berbeda. Pada pembobotan T2 TSE tanpa SENSE, teknik akuisisi dengan menggunakan turbo factor sehingga $K$ space terisi dengan cepat. Sedangkan pada pembobotan T2 sekuens TSE menggunakan SENSE tidak hanya menggunakan turbo factor, melainkan ditambah dengan pengurangan sampling time dari setiap elemen koil phased array, sehingga waktu akuisisi yang diperoleh menjadi lebih singkat hingga setengahnya dari waktu akuisisi standar tanpa menggunakan SENSE.

Hal ini sesuai dengan Westbrook dkk (2011), bahwa pada pembobotan T2 sekuens TSE standar tanpa menggunakan SENSE dengan penggunaan ETL antara 12 sampai 30 , beberapa baris $K$ space dapat terpenuhi dengan adanya turbo factor/ ETL sehingga $K$ space akan terisi penuh dengan cepat sehingga dengan terpenuhinya $K$ space dapat meningkatkan kualitas citra pada T2. Sedangkan pengurangan scan time pada pembobotan T2 sekuens TSE dengan menggunakan SENSE sesuai dengan Morelli dkk (2011), bahwa dengan SENSE tidak hanya menggunakan turbo factor yang panjang tetapi juga memanfaatkan elemen pada multipel koil penerima phased array dan mengurangi baris phase encoding pada $K$ space sesuai dengan faktor $1 / \mathrm{R}$ dimana $\mathrm{R}$ adalah reduction factor atau jumlah elemen pada koil phased array yang digunakan, sehingga sampling tidak mengisi semua $K$ space menjadikan waktu akuisisi data menjadi berkurang dan menjadi lebih cepat sesuai dengan $\mathrm{R}$ yang digunakan.

Menurut Ryan dkk (2005), bahwa teknik yang cepat memiliki keuntungan tidak hanya dari mengurangi adanya pergerakan, tetapi juga potensial untuk mengurangi waktu akuisisi. Teknik paralel imaging memiliki potensi tersebut yaitu dengan menggunakan sekuens yang cepat dengan penggunaan gradien yang dioptimalkan, sehingga potensial untuk mendapatkan pengurangan waktu akuisisi tanpa mengurangi efek yang signifikan pada kualitas citra diagnostik yang diperoleh.

Penggunaan teknik SENSE pada pembobotan T2 TSE pemeriksaan MRI brain potongan axial dapat digunakan sebagai pengganti pembobotan T2 TSE standar tanpa SENSE yang biasa digunakan, khususnya untuk pasien non kooperatif dari IGD yang membutuhkan waktu pemeriksaan yang cepat. Hal ini dikarenakan pengurangan waktu akuisisi pada teknik SENSE dapat meminimalisir terjadinya artefak karena pergerakan kepala pasien.

\section{SIMPULAN}

Ada perbedaan SNR pada pembobotan T2 TSE MRI brain potongan axial antara penggunaan SENSE dengan tanpa SENSE. Hal ini dikarenakan encoding antara kedua citra tersebut berbeda, pada citra T2 TSE tanpa SENSE terdapat penggunaan pulsa $180^{\circ}$ mendekati TE efektif sehingga shallow gradien menghasilkan echo maksimal, sedangkan pada citra T2 TSE menggunakan SENSE terdapat pengurangan baris phase encoding pada $K$ space dan adanya geometry factor menyebabkan SNR menjadi berkurang.

Ada perbedaaan scan time pada pembobotan T2 TSE MRI brain potongan axial antara penggunaan SENSE dengan tanpa SENSE. Hal ini dikarenakan teknik akuisisi antara kedua citra tersebut berbeda, pada citra T2 TSE tanpa SENSE terdapat ETL dalam pengisian $K$ space, sedangkan pada citra T2 TSE menggunakan SENSE terdapat reduction factor menyebabkan sampling tidak mengisi semua $K$ space sehingga waktu scanning menjadi berkurang.

\section{DAFTAR PUSTAKA}

American Association of Neurological Surgeons (AANS). 2006. Anatomy of the Brain. United States.

Bitar, Richard, General Leung, Richard Perng, Sameh Tadros, Alan R. Moody, Josee Sarrazin, Caitlin McGregor, Monique Christakis, Sean Symons, Andrew Nelson dan Timothy P. Roberts. 2006. MR Pulse Sequences : What Every Radiologist Wants to Know but Is Afraid to Ask, RSNA Volume 26, Number 2.

Dale, M. Brian, M.A Brown dan Richard C. Semelka. 2015. MRI Basic Principle and Applications, Fifth Edition. John Wiley and Sons Inc : New Jersey.

Dahlan, M. Sopiyudin. 2013. Statitiska Untuk Kedokteran dan Kesehatan. Salemba Medika : Jakarta

Edelman, Robert R. 2009. Fast Spin Echo. Softways : Magnetic Resonance Technology Information Portal : Wisconsin.

Elster, AD. 2015. Explain how does SENSE / ASSET work, Elster LLC. mriq.com

Gieseke, J, C. Kuhl, M. Von Falkenhausen, R. Blömer, O. Gür, G. Van Yperen, H. Schild dan G. Lutterbe. 2004. Ultra Fast T2-weighted TSE sequences with Flip Angle Sweep and SENSE at 3T. Proc. Intl. Soc. Mag. Reson. Med.

Glockner, James F, MD, PhD, Houchun H. Hu, BME, David W. Stanley, BS, Lisa Angelos, $\mathrm{PhD}$ dan Kevin King, PhD. 2005. Paralel Imaging : A User Guide. RSNA

Ichikawa, Tomoaki, Tabuaki Tsukamoto, Takatdi Kltamura, Ryauji Amemiya, Eiji Okamo'i, Kouji Miym dan Tsutomu Arak. 2002. Efficacy of A Combination of Sensitivity Encoding (SENSE) Technique with 3DMRCP Imaging with Balanced Turbo Field echo And Single shot Fast Spin-echo Sequences. Proc. Intl. SOC. Mag. Reson. Med.

Liney, Gary. 2006. MRI in Clinical Practice, Springer-Verlag London Limited.

Moeller, T.B dan Reif, E. 2007. Pocket Atlas of Sectional Anatomy Computed Tomography and Magnetic Resonance Imaging 3rd Edition revised and updated.

Morelli, John N, Val M. Runge, Fei Ai, Ulrike Attenberger, Lan Vu, Stuart H. Schmeets, Wolfgang R. Nitz dan John E. Kirsch. 2011. An Imagebased Approach to Understanding the Physics of MR Artifacts radiographics.rsna.org 
Neseth, R. 2000. Procedures and Documentation for CT and MRI. Medical Publishing Division, Kansas : McGraw-Hill.

Notoatmodjo, S. 2002. Metodologi Penelitian Kesehatan. PT. Rineka Cipta Jakarta.

Rasad, Sjahriar. 2011. Radiologi Diagnostik, Edisi Kedua, Gaya Baru. Balai Penerbit FKUI : Jakarta.

Ryan, M, Cunningham, P, Cantwll, C, Brennan, D dan Eustace, S. 2005. A comparison of fast MRI of hips with and without parallel imaging using SENSE. The British Journal of Radiology.

Sugiyono. 2007. Metode Penelitian Kuantitatif, Kualitatif dan R\&D. Alfabeta: Bandung.

Syaifudin. 1997. Anatomi Fisiologi untuk Siswa Perawat Edisi II, Buku Kedokteran. EGC : Jakarta.

Westbrook, C, Carolyne ,K Roth dan Talbot, J. 2011. MRI in Practice, Fourth Edition. Blackwell Science Ltd. : United Kingdom.

Westbrook, Catherine. 2014. Handbook of MRI Technique, Fourth Edition, Blackwell Science Ltd., United Kingdom

Weiger, Markus. 2000. Principles and Applications of Sensitivity Encoded Magnetic Resonance Imaging, Zurich.

Willineck, Winfried. A, Jurgen Gieseke, Marcus von Falkenhausen, Barbara Neuen, Hans H. Schild dan Christiane K. Kuhl. 2003. Sensitivity Encoding for Fast MR Imaging of the Brain in Patients with Stroke. RSNA.

Woodward, Peggy dan Freimarck, Roger. 2000. MRI for Technologists. McGraw-Hill, Inc : New York, USA 